\title{
Compartment Syndrome of the Hand from a Bullous Eruption
}

\author{
Phillip Braunlich D0*, Katherine Braunlich D0, Ryan Brink D0, Richard Miller D0, and John Harker Do \\ Departments of Orthopedic Surgery and Dermatology, Largo Medical Center, USA
}

Submission: November 24, 2019; Published: December 04, 2019

*Corresponding author: Phillip Braunlich, Departments of Orthopedic Surgery and Dermatology. Largo Medical Center, Largo, FL, D0. 201 14 ${ }^{\text {th }}$ St SW, Largo, FL 33770, USA

\begin{abstract}
Compartment syndrome of the hand can be a challenging diagnosis to ascertain. The difficulty in diagnosis is in part due to an absence of an established diagnostic criteria. Additionally, when a patient presents obtunded or with an altered sensorium the identification of compartment syndrome of the hand can be further complicated. Despite the potential difficulty in diagnosis, it's of upmost importance for orthopedic surgeons to recognize and treat this entity in an expeditious manner. Without prompt treatment, the risk to the patient is increased morbidity including possible amputation. Here within, we present a unique and thought-provoking case along with a review of the literature. The purpose of sharing this case is to highlight potential clues to aid in prompt diagnosis and improve patient outcomes.
\end{abstract}

Keywords: Bullae; Compartment syndrome; Edema; Fasciotomy; Hand

\section{Introduction}

Compartment syndrome occurs when interstitial pressure within a compartment prevents the tissue within from receiving adequate perfusion [1,2]. Ashton described when a critical threshold pressure is met, vessel collapse occurs as interstitial pressure exceeds that of intraluminal pressure. Venous congestion follows, ultimately leading to reduced perfusion and tissue necrosis [3]. Despite much literature on compartment syndrome of the lower extremity and forearm, the same cannot be said of that of compartment syndrome of the hand. Perhaps part of the reason is compartment syndrome of the hand is a perplexing diagnosis and one that does not have a set of concrete diagnostic criteria. Expedient recognition is necessary for the best possible outcome, as early identification may prevent muscle necrosis, contractures and amputation [4]. Some of the most common causes include trauma (i.e. fractures and crush injuries), snake envenomation, high-pressure injections, intravenous drug use, insect bites, and IV fluid extravasation [1]. Currently, the signs used to diagnosis compartment syndrome of the hand include extent of swelling, palpation of tense compartments and intensity of pain [4]. Another clue is the hand typically assumes an intrinsic minus position (MCP extension, PIP and DIP flexion; claw hand) [5]. This diagnosis becomes even more difficult in a patient with an altered sensorium, such as those on mechanical ventilation. This scenario removes the ability of the patient to provide a history, mechanism of injury or quantify pain on examination. At this point, the next step is measurement of compartment pressures, which will provide objective data. While the compartments of the extremities have a universal threshold value of within $30 \mathrm{mmHg}$ from the diastolic blood pressure or a measured absolute value of equal to or greater than $30 \mathrm{mmHg}$ for the diagnosis of compartment syndrome, the same cannot be said about the hand [6-10]. A review of the current literature reveals much debate regarding a strict diagnostic value for compartment syndrome of the hand. Table 1 summarizes this disparity in the literature. Regardless, it is imperative for the orthopedic surgeon to maintain a high level of clinical suspicion of compartment syndrome. Delayed or missed compartment syndrome has a devastating impact on the functional outcome of the patient, leading to necrosis, contractures and possibly the loss of the extremity.

Table 1: intra-compartmental pressures indicative of underlying compartment syndrome of the hand. Shown here is the wide variation evident in our current literature.

\begin{tabular}{|c|c|}
\hline Whitesides et al. & $50 \mathrm{mmHg}$ \\
\hline Matava et al. & $20 \mathrm{mmHg}$ within diastolic BP \\
\hline Heppenstall et al. & $30 \mathrm{mmHg}$ \\
\hline Ouellette et al. & $15-25 \mathrm{mmHg}$ \\
\hline
\end{tabular}

\section{Case Presentation}

60-year-old male admitted for routine sigmoidectomy secondary to multiple unresectable colonic polyps. Surgery was complicated by significant blood loss, conversion to open 
hemicolectomy and eventual transfer to the intensive care unit on mechanical ventilation. Dermatology and Orthopedic Surgery were consulted on post-operative day 2 and 3, respectively, for bullous edema of the left hand. Dermatology preformed punch biopsies of the bullous lesions and orthopedic surgery performed compartment pressure measurements using a Stryker needle device. The thenar and hypothenar compartments were found to have a pressure of $75 \mathrm{mmHg}$ and the remaining compartments of the hand had pressures $<20 \mathrm{mmHg}$. At this time, the decision to proceed with 10-compartment fasciotomy was made. Interestingly, the fourth dorsal interossei compartment musculature appeared non-viable and the hypothenar and thenar compartments had intra-compartmental hematoma, but viable musculature.

\section{Discussion}

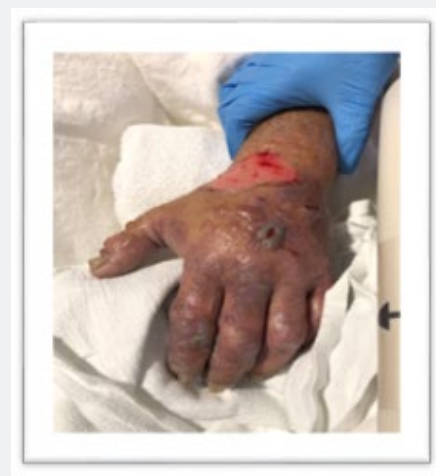

Figure 1

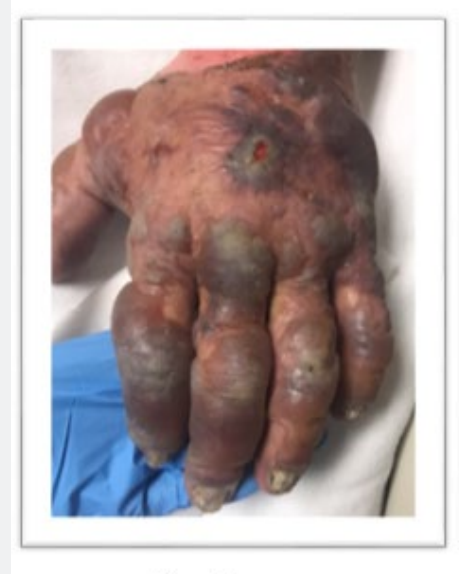

Figure 3

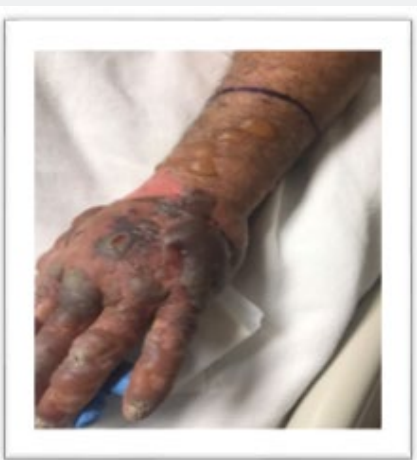

Figure 2

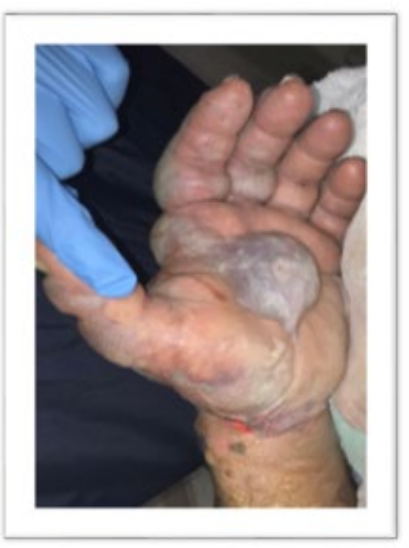

Figure 4

Figure 1: Clinical: edematous, erythematous to violaceous left distal extremity (hand > forearm) (1 \& 2). Hemorrhagic and serous bullae on the dorsal and ventral hand ( $3 \& 4)$. A $2 \mathrm{~cm}$ superficial ulcer on the dorsal hand (3).

The importance of prompt diagnosis and treatment of compartment syndrome is paramount for successful patient outcomes. Currently, the absence of established diagnostic signs and the lack of an absolute threshold compartment pressure complicates the delineation of compartment syndrome of the hand. We believe the development of an acute bullous eruption of the hand may be the presenting symptom for impending compartment syndrome. Bullous edema is indicative of a severe injury to the underlying soft tissue. The presence of this finding is especially helpful to aid in the diagnosis of patients who are unable to quantify pain or mechanism of injury. Tense compartments with the presence of bullous edema should raise concern for compartment syndrome of the hand, and perhaps should prompt the measurement of compartment pressures or even emergent fasciotomy. However, more research must be performed to establish not only a set of clinical findings, but also a consensus regarding diagnostic absolute compartment pressure and delta compartment pressures(Figure 1-4).

\section{Conclusion}

It is imperative to have a high level of clinical suspicion for compartment syndrome of the hand in patients with unexplained edema and hemorrhagic bullae. While an innovative set of diagnostic criteria and a consensus threshold of compartment pressures remains to be published, the available clinical history and clinical gestalt must allow the orthopedic surgeon to 
make a quick decision regarding treatment. Without prompt intervention, poor outcomes should be expected and are not limited to just necrosis and contractures, but possibly loss of limb or life.

\section{Conflict of Interest}

There is no financial interest or any conflict of interest to disclose.

\section{References}

1. Rubinstein, Aaron J, Irfan H Ahmed, Michael M Vosbikian (2018) Hand compartment syndrome. Hand clinics 34(1): 41-52.

2. Oak Nikhil R, Reid A Abrams (2016) Compartment syndrome of the hand. Orthopedic Clinics 47(3): 609-616.

3. Ashton Heather (1963) Critical closure in human limbs. British medical bulletin 19(2): 149-154.

4. Codding, Jason L, Michael M Vosbikian, Asif M Ilya (2015) Acute compartment syndrome of the hand. Journal of Hand Surgery 40(6): 1213-1216.
5. Halpern AA, Greene R, Nichols T, Burton DS et al. (1979) Compartment syndrome of the interosseous muscles: early recognition and treatment. Clin Orthop Relat Res 140(1979): 23-25.

6. Seiler III, John Gray, Scott P Olvey (2003) Compartment syndromes of the hand and forearm. Journal of the American Society for Surgery of the Hand 3(4): 184-198.

7. DiFelice Jr, Angelo, John Gray Seiler III, Thomas E Whitesides Jr (1998) The compartments of the hand: an anatomic study." The Journal of hand surgery 23(4): 682-686.

8. Spenny ML, Moen KY, Dinulos JG (2004) Acute bullous eruption with compartment syndrome due to intravenous infiltration. Archives of dermatology 140(7): 798-800.

9. Ouellette, Elizabeth Anne, Robert Kelly (1996) Compartment syndromes of the hand. JBJS 78(10): 1515-1522.

10. Whitesides TE, Haney TC, Morimoto K, Harada H, et al. (1975) Tissue pressure measurements as a determinant for the need of fasciotomy. Clinical orthopaedics and related research 113(1975): 4351.

\section{Your next submission with Juniper Publishers will reach you the below assets}

- Quality Editorial service

- Swift Peer Review

- Reprints availability

- E-prints Service

- Manuscript Podcast for convenient understanding

- Global attainment for your research

- Manuscript accessibility in different formats ( Pdf, E-pub, Full Text, Audio)

- Unceasing customer service

Track the below URL for one-step submission https://juniperpublishers.com/online-submission.php 